\title{
A Prospective Randomised Paired Trial of Sirolimus versus Tacrolimus as Primary Immunosuppression following Non-Heart Beating Donor Kidney Transplantation
}

\author{
John Asher ${ }^{\mathrm{a}} \quad$ Nikhil Vasdev $^{\mathrm{b}} \quad$ Hugh Wyrley-Birch $^{\mathrm{b}}$ Colin Wilson $^{\mathrm{b}}$ Naeem Soomro \\ David Rix $^{b} \quad$ Bryon Jaques $^{b} \quad$ Derek Manas $^{\mathrm{b}} \quad$ Nicholas Torpey $^{\mathrm{b}} \quad$ David Talbot $^{\mathrm{b}}$
}

aRenal Transplant Unit, Western Infirmary, Glasgow; ${ }^{b}$ Department of Hepatobiliary and Transplant Surgery,

Freeman Hospital, Newcastle upon Tyne, UK

\section{Key Words}

Transplantation

\begin{abstract}
Introduction: With calcineurin inhibitors potentiating damage from ischaemia-reperfusion injury in kidneys from donors after cardiac death we wanted to investigate the role of substituting sirolimus for tacrolimus in the delayed introduction of calcineurin inhibitor regime used in our centre. Method: A prospective randomised paired open-label study was performed taking pairs of kidneys from each donor and randomising one to a tacrolimus-based regime and the other to a similar regime based on sirolimus. Graft function at one year was the primary endpoint. Results: Total 31 pairs of kidneys were randomised to each group, with 19 pairs of recipients available for analysis after post-randomisation study exclusions. Despite a higher incidence of biopsy proven acute rejection in the sirolimus group, renal allograft function was similar in both groups at three-monthly intervals up to one year post-transplant. All episodes of acute rejection in the sirolimus group occurred in the first three months. Graft and patient survival at one year was $100 \%$ in the tacrolimus group, with one death with functioning graft in the sirolimus group (95\% survival). Unfortunately, 10 of the 19 patients in the sirolimus arm required switch of medication to tacroli-
\end{abstract}

\section{KARGER}

Fax +4161306 1234

E-Mail karger@karger.ch

www.karger.com
(C) 2013 S. Karger AG, Basel

$1015-9770 / 13 / 0074-0174 \$ 38.00 / 0$

Accessible online at:

www.karger.com/cur mus due to acute rejection or intolerable drug side effects. Conclusions: Graft survival and function were very similar in the two groups despite the higher rate of acute rejection in the sirolimus arm, raising the possibility that the damage done by acute rejection was adequately offset by the nephron-sparing effect of sirolimus compared to tacrolimus. Sirolimus may have a role as a longer-term maintenance immunosuppressant after initial treatment with a different agent such as tacrolimus or belatacept.

Copyright @ 2013 S. Karger AG, Basel

\section{Introduction}

The ever widening disparity between the demand for kidneys for transplantation and their availability from suitable donors continues to challenge the professional view of what is acceptable as a suitable donor, with growing interest particularly notable in donors after circulatory death, which now constitute more than $30 \%$ of deceased organ donors in the United Kingdom. Although it is now well established that long-term function from 
such donors is comparable to heart-beating donors after brain death $[1,2]$, even in cases of uncontrolled donation [3], early results tend to be inferior with increased rates of delayed graft function $[4,5]$ and primary non-function [6]. Delayed graft function to increased duration of hospital stay together with the risk of morbidity from dialysis, renal biopsies and healthcare-associated infection, while primary non-function results in patients who are sensitised as well as causing technical difficulties with access to vessels for re-transplantation.

The inferior early function in kidneys from donors after circulatory death is presumably a function of the increased ischaemia-reperfusion injury experienced by these kidneys, which the authors believe to be due to increased ischaemia arising from three separate factors. The first factor is pre-mortem renal hypoperfusion, due to hypotension in the agonal phase before cardiac arrest in both controlled and uncontrolled donors and the decreased cardiac output during cardiopulmonary resuscitation attempts in uncontrolled donors [7]. The second factor is the primary warm ischaemia between cardiac arrest and cold perfusion, and the third is the cold ischaemic time, which can be minimised by use of such manoeuvres as virtual crossmatching $[8,9]$ and retaining donor/donation after circulatory death (DCD) organs for local implantation. The increased ischaemia-reperfusion injury can be expected to increase the risk of acute tubular necrosis within the transplanted kidney, as well as endothelial injury leading to leakage and sequestration of pro-inflammatory mediators within the renal allograft. These deleterious effects may be exacerbated by further insults to the graft during the post-operative phase, including dehydration and nephrotoxic drugs, which are therefore avoided where possible.

Among the nephrotoxic drugs difficult to avoid are the calcineurin-inhibitors which so revolutionised the results of transplantation by their effectiveness in preventing and attenuating acute rejection. Among their side-effects is the promotion of vasoconstriction of the glomerular arterioles, increasing intra-renal resistance and reducing effective perfusion of the graft [10-12]. Strategies to minimise or avoid exposure to calcineurin-inhibitors in the immediate post-transplant period might therefore be expected to improve short-term outcome in DCD kidney transplantation, and indeed a prospective trial of using IL-2 receptor blockade to permit delayed introduction of calcineurin-inhibition in DCD kidneys has been published [13].

The mTOR inhibitor sirolimus, by providing an immunosuppressant effect similar to the calcineurin inhib- itors without nephrotoxic side effects [14-16], raised the enticing possibility of effective prophylaxis against rejection without compromise in function, and has been studied in numerous clinical trials. Although not nephrotoxic, sirolimus has been shown to delay recovery of function in the transplanted kidney exposed to ischemia-reperfusion injury [17], so a delayed introduction might prove advantageous. The Rapamycin Maintenance Regime trial showed improved GFR at 12 months where cyclosporin was withdrawn from a regime including sirolimus and steroids compared to a group where the cyclosporin was continued [15]. Flechner et al. [18] showed improved GFR at both 6 and 12 months when sirolimus was used to replace ciclosporin completely in a regime which also included induction therapy with basiliximab and maintenance treatment with mycophenolate mofetil. Based upon Flechner's study and our earlier work, we decided to conduct a study to assess the impact on transplant renal function of sirolimus versus tacrolimus, after delayed introduction, in DCD kidney transplantation.

\section{Methods}

We conducted a prospective randomised paired open-label study to compare the renal function in recipients receiving sirolimus or tacrolimus as maintenance immunosuppressants after DCD kidney transplantation.

\section{Inclusion/Exclusion Criteria}

We included all pairs of kidneys from locally retrieved donors after circulatory death. Pairs were excluded from the study if performed as a dual implant into one recipient, and individual kidneys were excluded if there was lack of patient consent to enrolment, if the kidney had failed prior to randomisation (from primary non-function or renal vein thrombosis), or if the patient was withdrawn from the trial due to side effects of the allocated treatment.

\section{Protocol}

To prevent increase in the duration of cold ischaemia arising from organ transportation, it is currently practice in the United Kingdom that DCD kidneys are retained locally for implantation, and thus we were able to obtain two kidneys from each donor, allowing a paired study.

Induction therapy was used in all patients in the form a single $2 \mathrm{mg} / \mathrm{kg}$ dose of the IL-2 receptor blocking antibody daclizum$\mathrm{ab}$ administered intravenously at the time of induction of general anaesthesia. Additionally, a 500mg intravenous dose of methylprednisolone was administered at the time of starting the arterial anastomosis.

Initial immunosuppression took the form of $20 \mathrm{mg}$ oral prednisolone and $2 \mathrm{~g} /$ day oral mycophenolate mofetil, starting as $1 \mathrm{~g}$ twice daily but with the option to change to $500 \mathrm{mg}$ four times daily if gastrointestinal side effects occurred, as unit experience suggests that such side effects are reduced by this dosage change. 
One kidney from each pair was randomised to a delayed introduction of tacrolimus and the other to a delayed introduction of sirolimus. The delayed introduction was defined as once the serum creatinine was less than $350 \mu \mathrm{mol} / \mathrm{l}(3.96 \mathrm{mg} / \mathrm{dl})$ or on the 10th postoperative day, whichever occurred first. Tacrolimus was administered as Prograf, with starting dose of $0.05 \mathrm{mg} / \mathrm{kg}$ twice daily, titrated to achieve a trough serum concentration of 5-10 $\mathrm{ng} / \mathrm{ml}$. Sirolimus was started at $2 \mathrm{mg} /$ day and the dosage was adjusted to achieve a trough level of 5-10 $\mathrm{mg} /$ day. This was later modified slightly to a target of 8-10 mg/day. One kidney was generally implanted first and therefore of a pair one had a shorter cold ischaemic time than the other. The randomisation was designed so that there was an equal number of 'first' transplants for each drug. Once tacrolimus or sirolimus was started, the mycophenolate mofetil dose was reduced to $1 \mathrm{~g}$ /day and prednisolone gradually reduced as per the normal unit protocol.

Outcome Measures

The primary endpoint of the study was renal function post-transplant, with creatinine clearance estimated by the Cockcroft-Gault formula. The rate of biopsy-proven acute rejection and patient and graft survival were secondary endpoints.

\section{Statistical Analysis}

Statistical analysis was performed using SPSS. Continuous variables were compared with the Wilcoxon sign rank test as a paired, non-parametric test, and categorical variables compared with the Chi-square test. A two-tailed p value of less than 0.05 was considered to demonstrate a statistically-significant difference.

As switches between the immunosuppressants due to side effects were expected, the primary endpoint of graft function was analysed both on an intention to treat and per protocol basis.

To achieve a power of $80 \%$ with an alpha of 0.05 for a 15 $\mathrm{ml} / \mathrm{min}$ difference in creatinine clearance, we calculated that we would need at least 30 patients in each group, based on the results of Flechner's study [18].

Ethical Approval

Ethical approval for this prospective study in line with the principles of the Declaration of Helsinki was obtained from the Newcastle and North Tyneside Local Research Ethics Committee, approval number 06/Q0906/50, EudraCT number 2006-00126541.

\section{Results}

Total 31 donor kidney pairs were planned for the trial, giving 31 kidneys in each group. Six patients were withdrawn from each group (3 renal vein thrombosis, 1 primary non-function, 1 death prior to hospital discharge and 1 non-used partner kidney in the tacrolimus group; 2 drug side effects, 2 acute rejection prior to randomisation, 1 lack of consent and 1 persisting acute tubular necrosis in the sirolimus group), resulting in the withdrawal of 12 pairs from the study and hence a total of 12 patients in each group. The exclusions are shown in table 1.
The 2 groups were well matched for recipient age and median ischaemic time. All were first transplant patients and none were re-transplants. More of the patients in the sirolimus groups were pre-emptive transplants prior to commencing dialysis ( 26 vs. $5 \%$ ), and there were more CMV donor positive to recipient negative mismatches in the tacrolimus group. Recipient characteristics are shown in table 2.

Ten of the 19 patients in the sirolimus group were switched to tacrolimus during the follow-up period of the study. The median time to switch was 2.5 months (range 1-11 months); 5 were switched for biopsy-proven acute rejection, of which all were within 3 months, 1 was switched for graft dysfunction at 4 months and the other 4 were switched due to side effects. None of the tacrolimus patients were switched to sirolimus. Switches are detailed in table 3 .

There were no statistically significant differences in median serum creatinine or calculated creatinine clearance between the two groups, either in the intention to treat or per protocol analysis. The graft function is shown in table 4 (intention to treat) and table 5 (per protocol).

Biopsy proven acute rejection occurred in 5 of the 19 patients randomised to sirolimus (26\%) and 2 of the 19 patients randomised to tacrolimus (11\%). Sirolimus levels at the time of rejection were $5.4 \mathrm{ng} / \mathrm{ml}$ for the first recipient, 3.8 and 7.0 at the time of the first 2 biopsies for the second recipient, 8.8 and 13.7 at the time of both biopsies for the third recipient and 5.8 and $16.3 \mathrm{ng} / \mathrm{ml}$ for the last 2 recipients respectively (according to the order of the recipients in table 3 ). Rejection occurred prior to starting tacrolimus in both recipients. The difference in rejection rate was not statistically significant $\left(\chi^{2}=0.700\right.$, $\mathrm{p}=0.403)$. Both patient and graft survival at one year were $100 \%$ in the tacrolimus group, while there was one death with functioning graft in the sirolimus group $(95 \%$ survival).

\section{Discussion}

The introduction of ciclosporin-based immunosuppression revolutionised transplantation, and can be said to the key milestone demarcating the boundary between the experimental era and the era of transplantation as routine, having largely solved the hitherto intractable problem of acute rejection. The impairment of longterm function has been cyclosporin's Achilles heel, but a problem the transplant surgeons of the 1970s would have welcomed as almost trivial compared to the burden 
Table 1. Exclusions from the trial

\begin{tabular}{lcc}
\hline & Tacrolimus $(\mathrm{n}=31)$ & Sirolimus $(\mathrm{n}=31)$ \\
\hline Total exclusions & 12 & 12 \\
Primary non-function & 1 & - \\
Healing problems (wound, urine leak) & - & 1 \\
Acute rejection before randomisation & - & - \\
Death prior to discharge & - & 1 \\
Mouth ulcers & 1 & - \\
Persisting ATN & - & 1 \\
Partner kidney not used & 3 & - \\
Consent refused & & \\
Renal vein thrombosis & & \\
\hline
\end{tabular}

Table 2. Recipient and donor characteristics

\begin{tabular}{lll}
\hline & Tacrolimus $(\mathrm{n}=19)$ & Sirolimus $(\mathrm{n}=19)$ \\
\hline Median recipient age & 49 & 49 \\
Predialysis & $5 \%(\mathrm{n}=1)$ & $26 \%(\mathrm{n}=5)$ \\
Re-grafts & $0 \%$ & $0 \%$ \\
2 DR mismatch & $5 \%$ & $0 \%$ \\
Median ischemic time (2nd WIT + CIT) & 1,261 mins $(21$ hours 01 mins $)$ & 1,360 mins $(22$ hours 40 mins) \\
Maastricht category II (uncontrolled donor) & $0 \%$ & $0 \%$ \\
CMV Mismatch (Donor Pos to Recip Neg) & $37 \%(\mathrm{n}=7)$ & $21 \%(\mathrm{n}=4)$
\end{tabular}

Table 3. Reasons for switches from sirolimus to tacrolimus (All the rejection episodes occurred in the first three months after transplant)

\begin{tabular}{lll}
\hline Recipient & Time post-transplant (months) & Reason for switch \\
\hline 1 & 1 & Banff 1b acute rejection \\
2 & 9 & Intractable oedema \\
3 & 1 & Banff 1b, Banff 2a, Banff 1a acute rejection \\
4 & 11 & Intractable oedema \\
5 & 2 & Banff 1a then Banff 1b acute rejection \\
6 & 7 & Arthralgia \\
7 & 3 & Overwhelming sepsis \\
8 & 4 & Graft dysfunction \\
9 & 2 & Banff 1a acute rejection \\
10 & 1.5 & Banff 1a acute rejection \\
\hline
\end{tabular}

of rejection seen in that era. Although perhaps easier to dose accurately, tacrolimus offers the same advantages and causes the same problems as ciclosporin. The CAESAR trial reinforced the value calcineurin inhibitors, showing increased rates of rejection in calcineurin in- hibitor withdrawal [19]. As a non-nephrotoxic [16] drug offering immunosuppression by a similar mechanism to the calcineurin inhibitors, sirolimus appeared to exhibit an enticing potential to be immunosuppressant of choice, especially as it is associated with a lower incidence of 
Table 4. Renal graft function on intention to treat basis

\begin{tabular}{|c|c|c|c|c|}
\hline Time & \multicolumn{2}{|c|}{ Tacrolimus $(\mathrm{n}=19)$} & \multicolumn{2}{|c|}{ Sirolimus $(\mathrm{n}=19)$} \\
\hline 6 months & $134(1.52)$ & 55.8 & $130(1.47)$ & 67.1 \\
\hline 9 months & $153(1.73)$ & 61.9 & $153(1.73)$ & 49.9 \\
\hline 12 months & $143(1.62)$ & 59.1 & $143(1.62)$ & 51.1 \\
\hline
\end{tabular}

${ }^{\mathrm{a}} \mathrm{GFR}$ is the creatinine clearance as estimated by the Cockcroft-Gault formula. None of these differences were statistically significant.

Table 5. Eenal graft function on per protocol basis

\begin{tabular}{|c|c|c|c|c|}
\hline Time & \multicolumn{2}{|c|}{ Tacrolimus $(\mathrm{n}=19)$} & \multicolumn{2}{|c|}{ Sirolimus $(\mathrm{n}=19)$} \\
\hline 6 months & $129(1.46)$ & 58.1 & $110(1.24)$ & 67.8 \\
\hline 9 months & $127(1.44)$ & 62.4 & $122(1.38)$ & 49.0 \\
\hline 12 months & $139(1.57)$ & 60.7 & $130(1.47)$ & 58.1 \\
\hline
\end{tabular}
cant.

${ }^{\mathrm{a}} \mathrm{GFR}$ is the creatinine clearance as estimated by the Cockcroft-Gault formula. None of these differences were statistically signifi-

Of the 19 patients in the sirolimus group, 10 were switched to tacrolimus and thus excluded from this analysis; the numbers of sirolimus group patients included was 14 at 3 months, 12 at 6 months, 11 at 9 months and 10 at 12 months.

post-transplant malignancy, but its side effect profile can be difficult to tolerate [20-23], leading to drug switches, and sadly long-term graft function was shown in the ELITE Symphony study inferior to use of low dose tacrolimus-based regimes [24].

In this trial, we were unable to demonstrate a difference in intermediate-term renal allograft function between use of tacrolimus and sirolimus-based regimes. This may be in part a reflection of power, as once pairs were excluded from the trial we were left with 19 pairs to analyse out of 30 that would be needed to achieve our a priori power estimates, and additionally 10 of the 19 patients in the sirolimus group were excluded from the per protocol analysis as they had been switched to tacrolimus. However, the actual median results were very similar, implying that there was no difference, although this study was not powered for a non-inferiority analysis.

For glomerular filtration rate those patients on sirolimus had an initial improvement of the order of $10.2 \mathrm{ml} /$ minute (59.7 vs. 69.9) which lasted 6 months and then the GFR declined for the few patients remaining on the sirolimus. This is broadly in line with the recently reported Zeus trial (Budde 2011) but a long way short of the difference of 15 as reported by Flechner that this trial was based on. In addition the Zeus trial took patients 4.5 months post transplant after initial cyclosporin, mycophenolate and steroid regime.

The A2309 study reduced calcineurin inhibitors (CNI) over one year in combination with everolimus and though they avoided rejection and adverse effects and achieved a $60 \%$ reduction of cyclosporin this did not change graft function. The pilot study of Holdaas of 20 kidney patients switched from cyclosporin to everolimus at week seven achieved an improvement of GFR from 51 to 58 in the short term with a $15 \%$ incidence of biopsy proven rejection.

These studies therefore reinforce the findings of this trial that though there is an improvement in GFR at least in the short term with sirolimus or everolimus this did not achieve the levels reported previously. Also most 
trials conducted since the original Flechner study have converted patients from a CNI regime sometime after the early transplant period. Our hope had been to continue from the CNI-free window used routinely in our centre for DCD kidneys to obtain graft recovery and then continue into a completely CNI-free regime. From our increased acute rejection rates it would suggest that either
CNI avoidance with just basiliximab was insufficient to cover this period. This could be overcome by either belatacept or alemtuzumab to cover this period of recovery. However the incidence of side effects related to the use of sirolimus and the only marginal improvement of GFR would question the routine early use of sirolimus for all recipients of DCD kidneys [29, 30].

\section{References}

-1 Nicholson ML, Metcalfe MS, White SA, Waller JR, Doughman TM, Horsburgh T, Feehally J, Carr SJ, Veitch PS: A comparison of the results of renal transplantation from non-heart-beating, conventional cadaveric and living donors. Kidney Int 2000;58:25852591.

2 Gok MA, Buckley PE, Shenton BK, Balupuri S, El-Sheikh M, Robertson H, Soomro N, Jaques BC, Manas DM, Talbot D: Long-term renal function in kidneys from non-heartbeating donors: a single-center experience. Transplantation 2002;74:664-669.

$\checkmark 3$ Gok MA, Asher JF, Shenton BK, Rix D, Soomro NA, Jaques BC, Manas DM, Talbot D: Graft function after kidney transplantation from non-heartbeating donors according to Maastricht category. J Urol 2004;172:23312334.

-4 Brook NR, Waller JR, Richardson AC, Bradley JA, Andrews PA, Koffman G, Gok M, Talbot D, Nicholson ML: A report on the activity and clinical outcomes of renal non-heart beating donor transplantation in the United Kingdom. Clin Transplant 2004;18:627-633.

-5 Asher J, Wilson C, Gok M, Balupuri S, Bhatti AA, Soomro N, Rix D, Jaques B, Manas D, Shenton B, Talbot D: Factors predicting duration of delayed graft function in nonheart-beating donor kidney transplantation. Transplant Proc 2005;37:348-349.

6 Balupuri S, Buckley P, Snowden C, Sen B, Griffiths P, Hannon M, Manas D, Kirby J, Talbot D: The trouble with kidneys derived from the non heart beating donor: a single center 10-year experience. Transplantation 2000;69:842-846.

7 Pernat A, Weil MH, Sun S, Tang W: Stroke volumes and end-tidal carbon dioxide generated by precordial compression during ventricular fibrillation. Crit Care Med 2003;31: 1819-1823.

-8 Zangwill S, Ellis T, Stendahl G, Zahn A, Berger S, Tweddell J: Practical application of the virtual crossmatch. Pediatr Transplant 2007;11:650-654.
-9 Bingaman AW, Murphey CL, Palma-Vargas J, Wright F: A virtual crossmatch protocol significantly increases access of highly sensitized patients to deceased donor kidney transplantation. Transplantation 2008;86:18641868.

10 Randhawa PS, Shapiro R, Jordan ML, Starzl TE, Demetris AJ: The histopathological changes associated with allograft rejection and drug toxicity in renal transplant recipients maintained on FK506. Clinical significance and comparison with cyclosporin. Am J Surg Pathol 1993;17:60-68.

-11 Randhawa PS, Tsamandas AC, Magnone M, Jordan M, Shapiro R, Starzl TE, Demetris AJ: Microvascular changes in renal allografts associated with FK506 (Tacrolimus) therapy. Am J Surg Pathol 1996;20:306-312.

$\$ 12$ Curtis JJ: Renovascular elements of the cyclosporin injury. Transplant Proc 1996;28:20942096.

-13 Wilson CH, Brook NR, Gok MA, Asher JF, Nicholson ML, Talbot D: Randomized clinical trial of daclizumab induction and delayed introduction of tacrolimus for recipients of non-heart-beating kidney transplants. $\mathrm{Br} \mathrm{J}$ Surg 2005:92:681-687.

14 Groth CG, Backman L, Morales JM, Calne $\mathrm{R}$, Kreis H, Lang P, Touraine JL, Claesson K, Campistol JM, Durand D, Wramner L, Brattström C, Charpentier: Sirolimus (rapamycin)-based therapy in human renal transplantation: similar efficacy and different toxicity compared with cyclosporin. Sirolimus European Renal Transplant Study Group. Transplantation 1999;67:1036-1042.

15 Johnson RW, Kreis H, Oberbauer R, Brattstrom C, Claesson K, Eris J: Sirolimus allows early cyclosporin withdrawal in renal transplantation resulting in improved renal function and lower blood pressure. Transplantation 2001;72:777-786.

16 Morales JM, Wramner L, Kreis H, Durand D, Campistol JM, Andres A, Arenas J, Nègre E, Burke JT, Groth CG: Sirolimus does not exhibit nephrotoxicity compared to cyclosporin in renal transplant recipients. Am J Transplant 2002;2:436-442.
17 Fuller TF, Freise CE, Serkova N, Niemann $\mathrm{CU}$, Olson JL, Feng S: Sirolimus delays recovery of rat kidney transplants after ischemia-reperfusion injury. Transplantation 2003;76:1594-1599.

18 Flechner SM, Goldfarb D, Modlin C, Feng J, Krishnamurthi V, Mastroianni B, Savas K, Cook DJ, Novick AC: Kidney transplantation without calcineurin inhibitor drugs: a prospective, randomized trial of sirolimus versus cyclosporin. Transplantation 2002;74:1070 1076.

19 Ekberg H, Grinyo J, Nashan B, Vanrenterghem Y, Vincenti F, Voulgari A, Truman M, Nasmyth-Miller C, Rashford M: Cyclosporin sparing with mycophenolate mofetil, daclizumab and corticosteroids in renal allograft recipients: the CAESAR Study. Am J Transplant 2007;7:560-570.

20 Campistol JM, de Fijter JW, Flechner SM, Langone A, Morelon E, Stockfleth E: mTOR inhibitor-associated dermatologic and mucosal problems. Clin Transplant 2010;24:149156.

-21 Tiong HY, Flechner SM, Zhou L, Wee A, Mastroianni B, Savas K, Goldfarb D, Derweesh I, Modlin C: A systematic approach to minimizing wound problems for de novo sirolimus-treated kidney transplant recipients. Transplantation 2009;87:296-302.

22 Goel M, Flechner SM, Zhou L, Mastroianni B, Savas K, Derweesh I, Patel P, Modlin C, Goldfarb D, Novick AC: The influence of various maintenance immunosuppressive drugs on lymphocele formation and treatment after kidney transplantation. J Urol 2004;171:1788-1792.

23 Flechner SM: Risk factors for and management of sirolimus-associated pneumonitis in kidney transplant recipients. Nat Clin Pract Nephrol 2008;4:250-251.

- 24 Ekberg H, Tedesco-Silva H, Demirbas A, Vitko S, Nashan B, Gurkan A, Margreiter R, Hugo C, Grinyó JM, Frei U, Vanrenterghem Y, Daloze P, Halloran PF: Reduced exposure to calcineurin inhibitors in renal transplantation. N Engl J Med 2007;357:2562-2575. 
-25 Vincenti F, Charpentier B, Vanrenterghem Y, Rostaing L, Bresnahan B, Darji P, Massari P, Mondragon-Ramirez GA, Agarwal M, Di Russo G, Lin CS, Garg P, Larsen CP: A phase III study of belatacept-based immunosuppression regimens versus cyclosporin in renal transplant recipients (BENEFIT study). Am J Transplant 2010;10:535-546.

-26 Larsen CP, Grinyo J, Medina-Pestana J, Vanrenterghem Y, Vincenti F, Breshahan B, Campistol JM, Florman S, Rial Mdel C, Kamar N, Block A, Di Russo G, Lin CS, Garg $\mathrm{P}$, Charpentier B: Belatacept-based regimens versus a cyclosporin A-based regimen in kidney transplant recipients: 2-year results from the BENEFIT and BENEFIT-EXT studies. Transplantation 2010;90:1528-1535.
27 Vincenti F, Larsen CP, Alberu J, Bresnahan B, Garcia VD, Kothari J, Lang P, Urrea EM, Massari P, Mondragon-Ramirez G, Reyes-Acevedo R, Rice K, Rostaing L, Steinberg S, Xing J, Agarwal M, Harler MB, Charpentier : Three-year outcomes from BENEFIT, a randomized, active-controlled, parallel-group study in adult kidney transplant recipients. Am J Transplant 2012;12: 210-217.

-28 Grinyo J, Charpentier B, Pestana JM, Vanrenterghem Y, Vincenti F, Reyes-Acevedo R, Apanovitch AM, Gujrathi S, Agarwal M, Thomas D, Larsen CP: An integrated safety profile analysis of belatacept in kidney transplant recipients. Transplantation 2010;90: 1521-1527.
29 Holdaas H, Bentdal O, Pfeffer P, Mjornstedt L, Solbu D, Midtvedt K: Early, abrupt conversion of de novo renal transplant patients from cyclosporin to everolimus: results of a pilot study. Clin Transplant 2008;22:366-371.

30 Budde K, Becker T, Arns W, Sommerer C, Reinke P, Eisenberger U, Kramer S, Fischer W, Gschaidmeier H, Pietruck F: Everolimus-based, calcineurin-inhibitor-free regimen in recipients of de-novo kidney transplants: an open-label, randomised, controlled trial. Lancet 2011;377:837-847.

31 Tadesco Silva Jr H, Cibrik D, Johnston T, Lackova E, Mange K, Panis C, Walker R, Wang Z, Zibari G, Kim YS: Everolimus plus reduced-exposure $\mathrm{CsA}$ versus mycophenolic acid plus standard-exposure CsA in renal-transplant recipients. Am J Transplant 2010;10:1401-1413. 